\title{
A Review of Cloud Computing Service Models
}

\author{
Karandeep Kaur \\ Assistant Professor \\ Dept. of Computer Science \\ Guru Nanak Dev University \\ Amritsar
}

\begin{abstract}
Cloud computing is a revolutionary technology that has brought about new luxuries in the field of Information Technology. It provides a source of data and application software storage in the form of huge data hubs called 'clouds', which can be accessed with the help of a network connection. These clouds help maximize the capabilities of enterprises without any extra set-up, personnel or licensing costs. Clouds are generally deployed using Public, Private or Hybrid models depending upon the requirements of the user. In this paper, the cloud computing architecture has been assessed, focusing on the various features of the Public, Private and Hybrid cloud models relevant to most individuals and organizations and how they support or hinder the operation of various cloud computing models. This paper intends to provide a bird's eye view of various characteristics of aforesaid models of cloud; which are put together side by side in order to facilitate the research study in this environment.
\end{abstract}

\section{General Terms}

Cloud computing, Public cloud, Private cloud, Hybrid cloud, Comparison of cloud models

\section{Keywords}

Literature Review, Cloud computing, Public cloud, Private cloud, Hybrid cloud, Comparison, Cloud Service Models, Cloud Deployment Models

\section{INTRODUCTION}

Cloud computing is an innovative architecture which provides resources to the user across the Internet while hiding the platform and other details using virtualization concept. The cloud service providers offer storage as well as computing resources at low costs. In this rapidly changing world of IT, where technologies like Big Data and Internet-of-things (IoT) are in the rage, to adapt is to survive, so the organizations are moving over to new business models. This transition has brought a lot of attention to cloud computing. It is also being followed by the concerns over its reliability and trust, primarily in terms of information security along with the various other challenges faced by cloud computing. This paper presents a comprehensive analysis of the cloud framework, identifying various characteristics of concern and comparing public, private and hybrid cloud based on them.

\section{CLOUD COMPUTING}

According to the official NIST definition ${ }^{[6]}$, "Cloud computing is a model for enabling ubiquitous, convenient, ondemand network access to a shared pool of configurable computing resources (e.g. networks, servers, storage, applications and services) that can be rapidly provisioned and released with minimal management effort or service provider interaction." Various SMEs and other organizations are benefitting from the cloud services due to the availability of the resources when the demand arises, hence removing the initial set-up costs and allowing scale up/down of resources in response to the fluctuations in demand.

In order to deliver the cloud services, the providers generally use three types of service models: Software, Platform and Infrastructure as well as four types of deployment models: Public, Private, Hybrid and Community cloud.

A brief description of the various types of service models is given below. All these models are deployed over the internet as a pay-per-use policy.

1. Software as a Service (SaaS): The cloud service providers give various software applications to the users, who can use them without installing them on their computer.

2. Platform as a Service (PaaS): The cloud service providers give platforms, tools and other services to the users.

3. Infrastructure as a Service (IaaS): The cloud service providers give infrastructure like storage, computing power etc. to the users through virtualization. $^{[8]}$

\subsection{Public Cloud}

It is a model in which the service providers make the resources available to the public users over the internet. It is owned by an organization selling cloud services. It may be free or implemented as pay-per-usage policy. Anyone can access the resources according to their demands and scale up/down on its basis. The biggest advantage of public cloud is the cost benefit it offers. There is no need for the SMEs (Small and Medium enterprises), organizations and individual users to set up any resources in advance; they can use them as and when required through the public cloud service providers by the means of a network connection. For example, Google, Amazon, Microsoft (Windows Azure), Apple (iCloud) etc. provide cloud services to the public users over the Internet.

\subsection{Private Cloud}

It is a model which provides cloud services to a private organization. It may be managed by the organization itself or a third party organization either on its premises or some other place away from it. Private clouds give the advantage of security to its organization, as all the data is stored on its own private servers, though the organization has to bear the initial set-up expenditure but its worth the security benefit it provides ${ }^{[16]}$. The scalability depends on the available resources and is limited unlike the public cloud, where unlimited resources can be utilized and high level of scalability can be achieved.

\subsection{Community Cloud}

It is a model in which cloud services are shared by multiple organizations and supports a specific community that has special concerns (e.g. mission, security considerations etc.). It 
may be managed by the organizations itself or some third party, either on-premise or off-premise.

This type of cloud also provides secure infrastructure for the participating organizations just like the private cloud.

\subsection{Hybrid Cloud}

It is a model which is a composition of two or more clouds (private, public, community). These clouds are separate entities which are bound by some standards or technology and enables data and application portability (e.g. load balancing during cloud bursting) ${ }^{[13]}$. Hybrid clouds offer the combined advantages of both public and private clouds. The scalability no longer depends on the private resources but can be extended into the public cloud resources if the need be. Similarly, the data security concern can be handled easily in hybrid cloud by keeping the sensitive and confidential data on the private servers.

\section{COMPARISON OF PUBLIC, PRIVATE AND HYBRID CLOUD}

There are many parameters which are under concern when we compare the different types of clouds. Generally, for small organizations that seek cost savings and test their software products before they are out in market, using public clouds is a good option as given by Khajeh-Hosseini et al. ${ }^{[1][2]}$. Private clouds are better suited for organizations that handle sensitive data and are apprehensive about its confidentiality ${ }^{[16]}$. For organizations which want to reap the benefits of both security as well as cost-effectiveness, hybrid clouds are appropriate. Depending upon the organization's priorities and needs, a particular cloud infrastructure can be chosen. The comparison has been shown in Table 1, based on some parameters which are of relevance to most of the SMEs and large organizations as well as individual users.

\subsection{Scalability}

One of the most important factor of consideration in cloud computing is the scalability. It has been one of the driving forces behind the innovation of clouds. Small and medium sized organizations can't afford to add up new resources if the demand arises, as they have cost considerations. Such organizations can benefit from public clouds as they can use the resources and pay for them according to the usage. Public clouds provide this advantage over private clouds. The private clouds offer limited scalability as it is owned by the organization itself and again is restricted by the price it can pay for the infrastructure. Hybrid clouds can provide high scalability as they can move to public clouds when the demand arises.

\subsection{Security}

Data security is an alarming challenge in cloud computing. Confidential and sensitive data can't be shared on a public platform. Therefore, such data is best kept on private servers in a private or hybrid cloud. Public cloud security presents a vague picture to its users. The storage of data at unknown locations as well as the level of security measures being taken at those locations, adds to their worries. The security in such clouds depends on the encryption and other authentication methods used by the public cloud service providers ${ }^{[12]}$. Security issues also sprout from hybrid clouds when they burst into public clouds. In such cases, utmost care has to be taken so that sensitive information is retained back rather than being passed on to the public cloud platform.

\subsection{Reliability}

Any cloud service provider faces a major question in the form of reliability of the services. Private clouds are always more reliable as all the service providing equipments, set-up and data is within the organization. Public clouds, however, do not offer that level of reliability as they depend on the availability of the service provider as well as the internet connection. Hybrid clouds provide a medium level of reliability as they combine the features of both public and private clouds as the most accessed data is kept within the organization.

\subsection{Cost of Use}

The biggest benefit of public clouds, as advertised by all their service providers, is the low cost of operation. It works on pay-as-you-use formula, so the consumer only pays for the services it uses. There is no cost of set-up involved, no capital investment; only an internet connection is required to start using all types of cloud services. It is emerging as a boon to the SMEs (small and medium sized enterprises) as it has considerably reduced their operating costs. On the other hand, if we talk about the private cloud owned by an enterprise itself, there is additional cost of set-up which the enterprise has to bear. The cost is high in this case. The hybrid cloud offers a medium level of cost, as the more expensive services can always be used from the public cloud platform and the rest can be deployed as a private cloud in the enterprise.

\subsection{Data and Application Integration}

Data and application integration is easier in public and private clouds as both use only one type of platform, whereas hybrid cloud faces difficulties in this matter as it combines both public and private platform features. Moving data from private to public cloud, keeping in mind the differences in protocols and interfaces of both the platforms, is a cumbersome task. Specially designed tools (e.g. VMware's vCloud) for cloud management are essential for this reason.

\subsection{System Management}

All the system management tasks like configuration management, monitoring, performance checks etc. are complex in hybrid clouds as compared to public or private clouds. The data and services are deployed across diverse environments/clouds; there is dissimilarity in the protocols and interfaces so a single system management tool does not suffice.

\subsection{Portability}

Due to the compatibility issues among the different cloud environments, the hybrid cloud infrastructure is said to be less portable than the others. Moving the data and configurations between environments is not an easy feat. It requires the use of special tools that can lead to seamless transfer between diverse environments.

\subsection{Tooling \& Skills}

Whenever a new technology comes up, it brings along a big demand for skilled people to work in that technology. The same is the case with cloud services. There is a need for experts, system designers and managers, especially in hybrid clouds as it is the latest among all cloud models. Public and 
Table 1: Comparison of Public, Private and Hybrid cloud ${ }^{[5]}$

\begin{tabular}{|c|c|c|c|c|}
\hline S. No & Characteristic & Public Cloud & Private Cloud & Hybrid Cloud \\
\hline 1. & Scalability & Very high & Limited & Very high, burst able \\
\hline 2. & Security & $\begin{array}{l}\text { Low; depends on } \\
\text { encryption techniques used } \\
\text { by service providers }\end{array}$ & High & Moderate \\
\hline 3. & Performance & Low to medium & Very good & Good \\
\hline & Reliability & $\begin{array}{l}\text { Medium, it depends on the } \\
\text { service provider availability } \\
\text { and connection to internet }\end{array}$ & $\begin{array}{l}\text { High, as many of the } \\
\text { equipments are } \\
\text { within the } \\
\text { organization }\end{array}$ & $\begin{array}{l}\text { Medium to high, as } \\
\text { replicated content is kept } \\
\text { within enterprises }\end{array}$ \\
\hline 5. & Cost of use & Pay-as-you-use & $\begin{array}{l}\text { High cost of initial } \\
\text { set up }\end{array}$ & Pay-as-you-use \\
\hline 6. & $\begin{array}{l}\text { Data \& Application } \\
\text { Integration }\end{array}$ & Easy & Easy & $\begin{array}{l}\text { Difficult due to change in } \\
\text { cloud platforms }\end{array}$ \\
\hline & $\begin{array}{l}\text { System } \\
\text { Management }\end{array}$ & $\begin{array}{l}\text { Easier as compared to } \\
\text { hybrid cloud }\end{array}$ & $\begin{array}{l}\text { Easier as compared } \\
\text { to hybrid cloud }\end{array}$ & $\begin{array}{l}\text { Difficult as compared to } \\
\text { public and private cloud }\end{array}$ \\
\hline 8. & Portability & Easy & Easy & Difficult \\
\hline & Tooling \& Skills & Easy & Moderate & $\begin{array}{l}\text { Difficult, as it's relatively a } \\
\text { new idea }\end{array}$ \\
\hline & $\begin{array}{l}\text { Data Security } \\
\text { Solutions }\end{array}$ & $\begin{array}{l}\text { Better encryption } \\
\text { techniques, authentication } \\
\text { of user by the provider }\end{array}$ & $\begin{array}{l}\text { Encryption of data } \\
\text { on private servers }\end{array}$ & $\begin{array}{l}\text { Encryption of personal data, } \\
\text { Sensitive data should not be } \\
\text { stored in public cloud }\end{array}$ \\
\hline & $\begin{array}{l}\text { Accountability } \\
\text { Solutions }\end{array}$ & $\begin{array}{l}\text { Moderate chances of } \\
\text { privacy violation }\end{array}$ & $\begin{array}{l}\text { Less chances of } \\
\text { privacy violation }\end{array}$ & $\begin{array}{l}\text { Audit needed in each step, } \\
\text { Data loss, leakage or privacy } \\
\text { violation may be dangerous }\end{array}$ \\
\hline 12. & Data Handling & $\begin{array}{l}\text { All the data is on public } \\
\text { platform }\end{array}$ & $\begin{array}{l}\text { All the data is on } \\
\text { private platform }\end{array}$ & $\begin{array}{l}\text { Confidential data is stored } \\
\text { on private servers to } \\
\text { respect country-specific } \\
\text { laws }\end{array}$ \\
\hline & Workload & $\begin{array}{l}\text { Normal workload with } \\
\text { short-term spikes in } \\
\text { demand }\end{array}$ & $\begin{array}{l}\text { Mission-critical } \\
\text { workload with } \\
\text { security concerns or } \\
\text { management } \\
\text { demands }\end{array}$ & $\begin{array}{l}\text { Highly dynamic or } \\
\text { changeable }\end{array}$ \\
\hline 14. & Capital Expense & Low & High & $\begin{array}{l}\text { Reduced, as the increase in } \\
\text { demand is outsourced to } \\
\text { public cloud }\end{array}$ \\
\hline 15. & Cloud bursting & Not supported & Not supported & Supported \\
\hline 16. & $\begin{array}{l}\text { Organizational } \\
\text { Agility }\end{array}$ & Moderate & Moderate & $\begin{array}{l}\text { Improved, from the ability } \\
\text { to leverage public clouds }\end{array}$ \\
\hline & $\begin{array}{l}\text { Network } \\
\text { Requirements }\end{array}$ & Works on internet & $\begin{array}{l}\text { Works on } \\
\text { organization's } \\
\text { intranet }\end{array}$ & $\begin{array}{l}\text { Needs to move from } \\
\text { intranet to internet }\end{array}$ \\
\hline
\end{tabular}

private clouds have been in the market for a longer time and there is more number of experts in these fields compared to hybrid cloud which is a naïve concept.

\subsection{Data Handling}

In cloud architecture, there are an increased number of access points of data because there are

a large number of parties, devices and applications involved. It can lead to data compromise. In private clouds however, all the data is stored on company's private servers so this risk is curbed. In public 
clouds, instead of data being stored on company's servers, data is stored on public service provider's servers which can be located anywhere in the world; therefore it is not suitable for sensitive data. Hybrid clouds need a different data handling strategy, confidential data is stored on private inhouse servers while the less sensitive data can be moved to and fro from the public clouds. Also, there may be violations of country-specific laws when data moves across countries. Hybrid cloud approach is a better solution as location-specific data can be kept within the region on private servers. ${ }^{[11]}$

\subsection{Workload}

Public clouds apparently came into existence to meet the short-term spikes in the demand of resources at an affordable price. The enterprises need not invest in any expensive equipment; they can get the required resources over the internet from the public cloud service providers and pay according to the time of use. Private clouds on the other hand, invest in the equipments and other resources because of their mission-critical needs as well as the security concerns etc. They can't rely on public cloud platform for their sensitive data storage. Hybrid clouds are generally deployed by enterprises with dynamic demands for resources. Due to the dynamic nature, they may need to burst into the public clouds from their secure private clouds.

\subsection{Cloud Bursting}

Cloud bursting is a phenomenon which is used synonymously with hybrid clouds. The enterprise can meet its basic needs by using the in-house resources, but can additionally scale up during its peak requirements phase by using the resources from a cloud provider i.e. the private cloud can burst into the public cloud to meet its needs. So the local as well as the public cloud resources can be effectively used along with the flexibility it offers to the enterprise ${ }^{[3]}$.

\section{CONCLUSION}

Cloud computing is a very promising technology which is enabling the enterprises to effectively manage their resource restraints with least amount of capital investment and meet dynamic demands efficiently. The security of data in cloud, however, is still an important area of research studies, with new techniques being proposed to instill confidence in the cloud users. Different cloud models can be chosen depending upon the specific needs of the enterprises as enlisted in Table1. It also highlights the strengths as well as the weaknesses of the three models. Data security, for example, is somewhat compromised in public cloud whereas private cloud is an expensive alternative to address the same issue. So somewhere down the line, we need to strike a balance between public and private cloud properties. Hybrid cloud model is a pragmatic solution for most of the issues of the enterprises and individuals. The paper also showcases different avenues of research aimed at improvising the characteristics of each cloud model.

\section{REFERENCES}

[1] Khajeh-Hosseini, A., Greenwood, , D., \& Sommerville, , I. (2010 a), Cloud Migration: A Case Study of Migrating an Enterprise IT System to IaaS, 3rd IEEE International conference on Cloud Computing, Cloud 2010, 5-10 July, Miami, USA.

[2] Khajeh-Hosseini, A., Sommerville, I., \& Sriram, I. $(2010$ b), "Research Challenges for Enterprise Cloud Computing”, LSCITS Technical Report.
[3] Bicer, T.; Chiu, D.; Agrawal, G., "A Framework for Data-Intensive Computing with Cloud Bursting," in Cluster Computing (CLUSTER), 2011 IEEE International Conference on , vol., no., pp.169-177, 2630 Sept. 2011

[4] Srinivasan, Aishwarya, Md Abdul Quadir, and V. Vijayakumar. "Era of Cloud Computing: A New Insight to Hybrid Cloud." Procedia Computer Science 50 (2015): 42-51. Web.

[5] Rao, T.Venkat, Kamsali Naveena, \& Reena David. "A New Computing Envornment Using Hybrid Cloud." Journal of Information Sciences and Computing Technologies [Online], 3.1 (1): 180-185. Web. 5 Mar. 2016

[6] Mell, P. M., and T. Grance. "The NIST Definition of Cloud Computing." (2011). Web.

[7] Prasad, Abhinandan S., and Shrisha Rao. "A Mechanism Design Approach to Resource Procurement in Cloud Computing." IEEE Transactions on Computers IEEE Trans. Comput. 63.1 (2014): 17-30. Web.

[8] Zissis, Dimitrios, and Dimitrios Lekkas. "Addressing Cloud Computing Security Issues." Future Generation Computer Systems 28.3 (2012): 583-92. Web.

[9] Balamurugan, B., and P. Venkata Krishna. "An Enhanced Security Framework for a Cloud Application." Advances in Intelligent Systems and Computing Artificial Intelligence and Evolutionary Algorithms in Engineering Systems (2014): 825-36. Web.

[10] Chang, Victor, Robert John Walters, and Gary B. Wills. "Cloud Computing and Frameworks for Organisational Cloud Adoption." Delivery and Adoption of Cloud Computing Services in Contemporary Organizations: 125. Web.

[11] Singh, Jatinder, Thomas Pasquier, Jean Bacon, Hajoon Ko, and David Eyers. "Twenty Cloud Security Considerations for Supporting the Internet of Things." IEEE Internet of Things Journal IEEE Internet Things J. (2015): 1. Web.

[12] Sood, Sandeep K. "A Combined Approach to Ensure Data Security in Cloud Computing." Journal of Network and Computer Applications 35.6 (2012): 1831-838. Web.

[13] Dillon, Tharam, Chen Wu, and Elizabeth Chang. "Cloud Computing: Issues and Challenges." 2010 24th IEEE International Conference on Advanced Information Networking and Applications (2010). Web.

[14] Kaur, Anureet. "An Age of Cloud in Mobile Computing (Mobile Cloud Computing)."

[15] Moura, Jose, and David Hutchison. "Review and Analysis of Networking Challenges in CloudComputing." Journal of Network and Computer Applications60 (2016): 113-29. Web.

[16] Chang, Victor, Robert John Walters, and Gary B. Wills. "Cloud Computing and Frameworks for Organizational Cloud Adoption." Delivery and Adoption of Cloud Computing Services in Contemporary Organizations: 125. Web. 